\title{
Predictive factors of neonatal mortality in intensive neonatal care unit at Goma Eastern Democratic Republic of Congo
}

\begin{abstract}
Background: The neonatal mortality rate is still significant public health problem in Sub-Saharan Africa countries and major contributor to higher under-five deaths globally. Objective of this study was to identified and analyzed the different maternal and neonates risk factors associated to neonatal mortality in our study environment

Methods: This research was case-control study from January1st, 2010 to December31, 2013. It's was conducted at intensive neonatal care unit of North-Kivu Provincial Hospital, in Goma, Eastern Democratic Republic of Congo at the. Case were neonates deaths $(n=183)$ and control group were twice infants born alive immediately following or preceding the case $(n=366)$.

Results: Intra-hospital neonatal mortality rate was $19.7 \%$.Analysis of the various risk factors associated with newborns revealed that the gestational age of the newborn $<37$ weeks $\mathrm{OR}=1.13(0.79-1.61)$, low birth weight $<2500 \mathrm{gr}$ OR=1.01(0.71-1.43) ,Apgar score $<7 \quad \mathrm{OR}=1,01 \quad(0,64-1,84)$, referral neonates $\mathrm{OR}=5,12(3,40-7,71)$ are real predictor factors of neonatal mortality. Maternal age, less than 18 and more than 35 years $\mathrm{OR}=9.65$ (5.34-17.04), maternal occupation housewife $\mathrm{OR}=13.41$ (6.63-27.11); maternal education level low $\mathrm{OR}=4.3$ (2.86 -6.47) are real maternal determinants of neonates deaths.

Conclusion: This study noted that neonatal mortality was influenced by preventable maternal factors (age, antenatal visit care; urogenital infection and poverty) and also, neonatal factors (low birth weight, sex and newborn age).According quality prenatal, natal and postnatal care would reduce the rate of neonatal deaths in our area study.
\end{abstract}

Keywords: risk factors, newborn, neonatal death, survival
Volume 9 Issue 2 - 2019

\author{
Mashako RM,' Ngbonda D,' Alworong'a OJ,' \\ BitweM R, ${ }^{2}$ Mashako KY, ${ }^{3}$ Nsibu NC, ${ }^{4}$ \\ 'Pediatric Department, Faculty of Medecine and Pharmacie, \\ Kisangani University, Democratic Republic of the Congo \\ ${ }^{2}$ Pediatrc Department, Faculty of Medecine and Pharmacie, \\ Goma University, Democratic Republic of the Congo \\ ${ }^{3} \mathrm{HIV}$ and AIDS Officer United Mission in South Soudan and \\ Biomedicine research National Institute in DRC, Democratic \\ Republic of the Congo \\ ${ }^{4}$ Pediatrc Department, Faculty of Medecine and Pharmacie, \\ Kinshasa University, Democratic Republic of the Congo
}

Correspondence: Many Mashako Ruhanga, Pediatric Department, Faculty of Medecine and Pharmacie, Kisangani University, Democratic Republic of the Congo, Email manymashako@gmail.com

Received: February 01, 2019 | Published: March 27, 2019

\section{Introduction}

The millennium Development Goals (MDGs) in 2015 have not been achieved. ${ }^{1}$ Neonatal death is defined as newborn death occurring within the first four weeks after birth. ${ }^{2,3}$ The first 28 days of life or the neonatal period is most vulnerable time for child's survival. Globally 2.5 million children died in the first month of life in 2017. 1 million dying on the first day and close to 1 million dying within the next six days. ${ }^{4} \mathrm{~A}$ vast majority of global neonatal deaths take place in the in developing countries while approximately $70 \%$ of these deaths occur in just two World Health Organization: Africa and south-East Asian., ${ }^{5,6}$ In Sub-Saharan Africa alone 1.2 million newborns died every year equivalent to 13000 deaths per days or almost nine death every minutes. ${ }^{7,8} 50 \%$ of neonatal deaths occur in just five countries: Nigeria, Democratic, Republic of Congo, Ethiopia, Tanzania and Uganda. Majority of neonatal deaths in this party of Africa occur at home, ${ }^{9}$ in rural communities, ${ }^{10}$ among the poor and poorest, ${ }^{11}$ less educated, ${ }^{12,13}$ and in war regions. ${ }^{14-16}$ Also causes and risk factors of neonatal death vary by country with the availability in relation with quality of health care. ${ }^{13}$ Democratic Republic of Congo, ranks second among Africa countries with higher neonatal mortality rate more than 28 per 1000 live births. ${ }^{17,18}$ Understanding those neonatal mortality factors is crucial to realize sustainable development goal in this country. Objective of this study was undertaken to assess maternal and neonatal risk factors of neonate's deaths in Goma, East Democratic Republic of Congo.

\section{Methods and material}

This retrospective case-control study was conducted at intensive neonatal care unit of North-Kivu Provincial Hospital, in Goma, Eastern Democratic Republic of Congo, which is one of the reference health facilities child health care in this region. That neonatology unit has two sections, one for preterm infants with 11 incubators and second section for term neonates with capacity of 14 cots. The unit is taken care by 4 pediatricians, 8 general practitioner and 14 nurses' staff. This retrospective, descriptive study covering a period of forth years extending from January 1st, 2010 to December 31, 2013. During our study period, 927 neonates were admitted at intensive neonatal care unit. Case was 183 neonates who died within the first 28 days of their lives in our study sites. Control group had twice the size of case group. 366 neonates survival randomly selected. Inclusion criterion was neonatal death within the study period. All neonates who died on arrival or with empty or incomplete files were excluded from the study. 17 neonates were excluded from the study. Data were collected by trained from medical records in both case and control group. Variable of the interest was neonate's variables (sex, birth weight, Apgar score; admission mode; causes and moment of death); maternal variables were (Maternal age, occupation; level education; marital status; antenatal care visit and urogenital infection). A Microsoft Excel-based data served as the data source for the study. The data were statistically analyzed using the spss version 20. Odds ration were applicated in this study to assess the neonates and maternal risk factors associated 
within neonatal mortality. Authorization to carry out the study, and ethical clearance were obtained from the hospital authorities and the hospital ethics committee. The data were kept confidential.

\section{Findings}

\section{Mortality rate}

During our study period, among 923 newborns was admitted in the neonatology unit; 183 newborns was died; $107(58.5 \%)$ of them were females and 76(41.5\%) males. The neonatal intra-hospital neonatal mortality rate was $19.7 \%$.

\section{Mortality rate}

During our study period, among 923 newborns was admitted in the neonatology unit; 183 newborns was died; $107(58.5 \%)$ of them were females and $76(41.5 \%)$ males. The neonatal intra-hospital neonatal mortality rate was $19.7 \%$.

\section{Newborn risk factors associated within neonatal mortality}

Table 1: Analysis of the various risk factors associated with newborns revealed that the gestational age of the newborn inferior to 37 weeks $\mathrm{OR}=1.13(0.79-1.61)$, low birth weight $<2500$ gr $\mathrm{OR}=1.01(0.71-1.43)$ are real risks factors.

Table I Newborn factors associated within neonatal mortality

\begin{tabular}{|c|c|c|c|c|}
\hline \multicolumn{2}{|r|}{ Case } & \multicolumn{3}{|c|}{ Control group } \\
\hline Factors & $N=183(100)$ & $N=366(100)$ & OR IC $95 \%$ & $P<0,05$ \\
\hline \multicolumn{5}{|c|}{ Age (weeks) } \\
\hline$<=37$ & $90(49.2)$ & $189(51.7)$ & 1.13 [0.79-1.6I]. & S \\
\hline$>37$ & $93(50.2)$ & I77(4 8.3) & & \\
\hline \multicolumn{5}{|l|}{ Gender } \\
\hline Males & $76(4 \mid .5)$ & $|7|(46.7)$ & $0.86[0.57-1.17]$ & $S$ \\
\hline Females & $107(58.5)$ & $195(53.3)$ & & \\
\hline \multicolumn{5}{|c|}{ Weight (gr) } \\
\hline$<2500$ & $95(51.9)$ & $189(51.6)$ & I,0।[0.7I-I.43]. & S \\
\hline$>=2500$ & $88(48.1)$ & I77(48.4) & & \\
\hline
\end{tabular}

Table 2: Apgar scoreless $7 \mathrm{OR}=1,01(0,64-1,84)$, referral neonates $\mathrm{OR}=5,12(3,40-7,71)$ are real also risk factors of neonatal deaths also.

Table 2 Neonates factors associated with neonatal death

\begin{tabular}{|c|c|c|c|c|}
\hline \multirow[b]{2}{*}{ Factors } & \multirow{2}{*}{$\begin{array}{l}\text { Case } \\
N=183\end{array}$} & \multicolumn{3}{|c|}{ Control group } \\
\hline & & $N=366$ & OR IC 95\% & $P<0,05$ \\
\hline \multicolumn{5}{|l|}{ Apgar } \\
\hline$<7$ & $14(0.77)$ & $24(06.6)$ & I.08 [0.64-1.84]. & S \\
\hline$>=7$ & $169(98.2)$ & 159(93.4) & & \\
\hline \multicolumn{5}{|l|}{ Admission } \\
\hline Referral & $86(47)$ & 68 & 5.12 [3.4-7.7I]. & S \\
\hline No referral & $97(53)$ & 298 & & \\
\hline \multicolumn{5}{|l|}{ Delivery } \\
\hline Caesarean & $43(23.5)$ & $120(35.2)$ & & Protective \\
\hline Eutocic & $140(76.5)$ & $237(64.8)$ & & \\
\hline
\end{tabular}

\section{Maternal risks factors determining neonatal mortality}

Table 3: Maternal age, less than 18 and more than 35 years $\mathrm{OR}=9.65$ (5.34-17.04), maternal occupation housewife $\mathrm{OR}=13.41$ (6.63-27.11); maternal education level low $\mathrm{OR}=4.3(2.86-6.47)$ and Table 4: number of prenatal consultation $<4$ OR=9.59 (6.38-14.42), marital status no married $\mathrm{OR}=3.38$ [2.13-5.37], anogenital infection during pregnancy $\mathrm{OR}=3.78(2.60-5.50)$ and parent poverty 21.74 [13.73-34.42] are real déterminants of neonataldeaths.

Table 3 Maternal risk factors associated with neonatal mortality

\begin{tabular}{|c|c|c|c|c|}
\hline \multirow[b]{2}{*}{ Factors } & \multirow{2}{*}{$\begin{array}{l}\text { Case } \\
N=183\end{array}$} & \multicolumn{3}{|c|}{ Control Group } \\
\hline & & $N=366$ & OR IC $95 \%$ & $P<0,05$ \\
\hline \multicolumn{5}{|l|}{ Age (years) } \\
\hline$<18$ and $>35$ & $70(38.3)$ & $63(17.2)$ & $2,98[1,99-4,46]$. & $S$ \\
\hline $18-35$ & $1 \mid 3(6 \mid, 7)$ & $303(82.8)$ & & \\
\hline \multicolumn{5}{|l|}{ Occupation } \\
\hline House wife & $174(95.1)$ & $20 I(54.9)$ & $|3.4|[6.63-27 .||]$. & S \\
\hline Other & $09(4.3)$ & $165(45.1)$ & & \\
\hline \multicolumn{5}{|l|}{ Education level } \\
\hline No and primary & | $44(78.7)$ & $169(46.2)$ & $4.3[2.86-6.47]$. & S \\
\hline Secondary and + & $39(21.3)$ & $197(53.8)$ & & \\
\hline
\end{tabular}

Table 4 Mother's risk factors associated with neonatal mortality

\begin{tabular}{|c|c|c|c|c|}
\hline \multirow[b]{2}{*}{ Factors } & \multirow{2}{*}{$\begin{array}{l}\text { Case } \\
N=183 \\
(100)\end{array}$} & \multicolumn{3}{|c|}{ Control group } \\
\hline & & $\begin{array}{l}N=366 \\
(100)\end{array}$ & OR IC 95\% & $P<0,05$ \\
\hline \multicolumn{5}{|l|}{ Prenatalvisit } \\
\hline$<=3$ & $129(70.5)$ & $73(19.9)$ & $9.59[6.38-\mid 4.42]$ & S \\
\hline$>3$ & $54(29.5)$ & $293(80.1)$ & & \\
\hline \multicolumn{5}{|l|}{ UGI(I) } \\
\hline Present & $107(58.5)$ & $98(26.8)$ & $3.78[2.6-5.5]$ & S \\
\hline Absent & $76(4 I .5)$ & $268(73.2)$ & & \\
\hline \multicolumn{5}{|l|}{ Marital Status } \\
\hline No married & $54(29.5)$ & $39(10.7)$ & $3.38[2.13-5.37]$ & S \\
\hline Married & $129(70.5)$ & $327(89.3)$ & & \\
\hline \multicolumn{5}{|l|}{ Povrety } \\
\hline Yes & $136(74.3)$ & $43(11.7)$ & $21.74[13.73-34.42]$ & S \\
\hline No & $47(25.7)$ & $323(88.3)$ & & \\
\hline
\end{tabular}

UGI(1), Uro-genital Infection

\section{Discussion}

\section{Neonatal mortality rate}

Neonatal mortality rate is an indicator of public health, reflects the demographic, biological; cultural and economic status of the population and also represents the growth trend and public health of population. ${ }^{19,20}$ During our study period 183 deaths was noted out of 927 neonates admitted to the neonatology intensive care unit. Intrahospital neonatal mortality rate was $19,7 \%$. However, this is in contrast to the Higher rates noted by others authors Nagalo K et al., ${ }^{19} 28.3 \%$ and Kateng A et al., ${ }^{20} 36,9 \%$ This could be due to poverty and ignorance prevailing in these countries which limit access to antenatal, intra-partum and postnatal care of quality. 


\section{Risk factors associated with newborn}

This study revealed statistically significant relation between newborn gestational age inferior to 37 weeks, low birth weight $<2500$ gr Apgar scoreless 7, referral neonates. This finding corroborates findings of several authors. ${ }^{21-23}$ Gestational age $<37$ weeks is known to contribute to higher neonatal death compared with term new born and attributes this directly to specific complication like breathing difficulties, intracranial bleeds neonatal sepsis, hypothermia and jaundice. ${ }^{24}$ Also Li et al., ${ }^{25}$ fund a relationship between five minutes Apgar score, which is predictive value for infant death of both very preterm, preterm and term newborns in post neonatal period. They concluded that the Apgar score could still be a good and convenient predictor of neonate's death. Preterm and post term are unable to adjust extra uterine life and are exposed to specific neonatal complications.

\section{Maternal risk factors associated with neonatal death}

The Results of the curent study showed that the maternal age, less than 18 and more than 35 years, housewife, uneducated monther, insufficient antenatal care, marital status, anogenital infection during pregnancy and poor socio-economic status are real déterminants of neonataldeaths. Similar results was observed by others authors. ${ }^{25-27}$ A common supporting argument is that maternal education increases mother's knowledge about child health and health care services, therely improves health care seeking behaviours for their children and themselves contrary to the widely held expectation, more training programs should be provided to improve the neonatal health care in mothers. Also, employed mothers should be encouraged to spend more time before and after childbirth.

\section{Conclusion}

The neonatal mortality was influenced by maternal and newborns factors which related to prenatal, natal and postnatal care. Such factors are reducible through health sector action. A correct-take care of the pregnancy and the new born in his first week of life should improve the vital prognostic neonatal. The current study findings could be utilized to determine priorities, planning, evaluating of services, and improving the health care for mothers and the neonates.

\section{Competing interests}

The authors declare that they have no competing interests.

\section{Authors' contributions}

All authors participated to collect the data, performed the statistical analysis; wrote the draft of the paper and were involved in critically revising the manuscript for important intellectual content. All authors read and approved the final manuscript.

\section{Acknowledgments}

Authors appreciate very much the support of KayembeTshilumba Charles and Katenga Bosunga Gédeon, Kisangani University hospital; respectively in internal department and obstetrics and gynecology department, for their suggestions and priceless comments witch made this work a great success. Sincerely thanks.

\section{Financial support}

This study was supported by authors.

\section{References}

1. Shikha M, Gohiya P, Khan AI. Morbidity profile and mortality of neonates admitted in neonatalntensive care unit of central India Teaching Institute: A prospective observational study. J Clin Neonat .2016;5(3):168-173.

2. Ahman E, Zulpan J, Safer W. Neonatal and global estimates Geneva. World Health Organization; 2007.

3. Yego F, D'Este C, Byles J, et al. A case-control study of risk factors for fetal and early neonatal deaths in tertiaty Hospital in Kenya. BMC Pregnancy Childbirt. 2014;14:389.

4. United Nations Children's Funds. Neonatal mortality: 2018.

5. Hebert H, Lee A, Chandran A, et al. Care seeking for neonatal illness in low and middle income countries: Asystematicsreview. Plos Med. 2017;9(3):e1001183.

6. Afolabi BM. Subsaharan African neonates-Ghosts to statistics. $J$ Neonatal Biol. 2017;6:1.

7. Siobhan D, Guy T, Liliana C, et al. Every child alive: the urgent need to end newborn deaths. United Nations. Children's Fund. Switzerland: 2018 .

8. Susan Niermeyer. Global neonatal survival, every newborns; an action plan to end preventable deaths. United Nations. Children's Fund. Switzerland: 2018.

9. Maternal-child-adolescent, newborns, management and illness complications: 2018.

10. Kannura R, Tetui M, Mutebi A, et al. The neonatal mortal mortality and it's determinants in rural communities of Eastern Uganda. Reproductive Health. 2016;13:13.

11. Osita K, Emwinyore A, Dibley M, et al. Determinants of neonatal mortality in Nigeria: Evidence from the 2008 demographic and health survey. BMC Public Health. 2014;14:521.

12. Ndayisenga T. Maternal and newborn risk factors associated with neonatal mortality in Gitwe district hospital in Ruhango district, Rwanda. Int J Med Publ Health. 2016;6(2):98-102.

13. Imitiaz J, Harris $\mathrm{H}$, Salat $\mathrm{S}$, et al. Neonatal mortality risk factors and causes: A prospective population- based cohort study in Urban Pakistan. Bull World Health Org. 2009;87(2):130-138.

14. Lindskog E. Effet of war on infant mortality in the Democratic Republic of Congo. BMC Public Health. 2016;16:1059.

15. Kiros G, Hogan D. War, famine and excess child mortality in Africa:The role of parental education. Int J Epidem. 2001;30(3):447-455.

16. Imelda KM. Causes of Morbidity and mortality among neonates and children in post-conflits Burundi: A cross-selectionnal retrospective study. Children (Basel). 2018;5(9):E125.

17. Democratic Republic of Congo Demographic and survey 2013-2014.

18. Maternal and new born health disparities: Democratic Republic of Congo: 2018.

19. Nagalo K, Dao F, Tall FH. Ten years morbidity and mortality of newborns hospitalized at the Clinic El-FatehSuka (Ouagadougou, Burkina Faso). Pan Afr Med J. 2013;14:153.

20. Kateng A, Nyenga A, Lubala $\mathrm{T}$ et Col. Neonatal mortality in the neonatology unit of university hospital of Lubumbashi. Gdlacs. Afr Health Sci. 2012;1(4):232-244.

21. Welbeck J, Biritwum R, Mensah G. Factors affecting the survival of a risk newborn at Korle Bu Teaching Hospital Accra, Chana. West Afr J Med. 2003;22(1):21-27. 
22. Khashu M, Narayanan M, Bhargava S, et al. Perinatal outcomes associated with preterm birth at 33 to 36 weeks gestation: A populationbased cohort study. Pediatrics. 2009;123(1):109-113.

23. Ghotbi N, Zokai M, Rahmani K, et al. Risk factors related to the Neonatal mortality in Kurdistan Province Iran: A population-based case-control study. Shiraz E Med J. 2017;18(3):e44155.

24. Annan G, Asiedu Y. Predictors of neonatal deaths in Ashanti region of Ghana: A cross-selectional study. Public Health. 2018;11.
25. Li F, Wu T, Lei X, et al. The Apgar score and infant mortality. Plos One 2013;8(7):e69073

26. Lukonga E, Michelo C. Factors associated with neonatal mortality in the general population: evidence from the 2007 survey Zambia Demographic and health survey a cross sectional study. Pan Afr Med J. 2015; 20:64.

27. Macassa G, Hallqvist J, Lyne J. Inequalities in child mortality in SubSaharan Africa. A social epidemiological framework. Afr $J$ Health Science. 2011;18(12):14-26. 